\title{
$7 \quad$ Youth safety in public transportation
}

\section{The case of eastern Mexico City, Mexico}

\author{
Javier Romero-Torres and \\ Vania Ceccato
}

\subsection{Introduction}

Worldwide, women are more likely than men to be exposed to unwanted sexual behavior while in transit and in public transportation (PT). This is partially because women travel by public transport more often than men do. In some countries, women constitute the so-called "transit captives", whereby they have limited access to non-public forms of transportation (such as private cars) and are therefore overly reliant on PT. The \#MeToo! Movement has shown that sexual harassment and sexual violence can happen anywhere, and in some public environments, such as buses and trains, they may include unwanted sexual behaviors that are often normalized by social and cultural norms. Given this, addressing the issue of sexual harassment has become an increasing part of the public transportation agenda (Ceccato \& Loukaitou-Sideris, 2020).

This chapter reports the experiences of sexual victimization, the safety perceptions of public transportation (PT), as well as a discussion of safety precautions taken by young people in eastern Mexico City, Mexico. The analysis is based on a survey of 381 university students collected in 2018 from the CU Nezahualcóyotl campus. The CU Nezahualcóyotl campus is located to the east of the metropolitan area of Mexico City. The metropolitan area was classified in 2012 by the United Nations as being the third most populated area of the world (UN-Habitat, 2012). Its PT ridership encompass over 15 million daily trips, which include over one million daily trips within the municipality of Nezahualcóyotl (INEGI, 2017).

Poor transit safety is a major social issue in Mexico City. A survey conducted by Reuters revealed that the transportation system of Mexico City was considered as the second most dangerous in the world (TRF, 2014) and that up to 90 percent of women riders of PT declared being victims of sexual assault, with most being young women (CONAPRED, 2009). Given this, the focus of this study is to analyze victimization and perceptions of safety among this age group in the bus and Metro system.

Sexual crimes encompass various types of sexual behaviors which can vary from sexual harassment to sexual assault, and to further complicate matters, the 
boundaries between these types of acts are blurred. In this study, we follow the definition suggested by Ceccato and Loukaitou-Sideris (2020):

1. Nonverbal sexual violence/abuse. It includes exhibitionism, showing sexually explicit pictures, or making sexual gestures.

2. Verbal sexual violence/abuse. It includes sexual comments, jeering or taunting, and asking questions about sexual activity.

3. Physical sexual violence/abuse. It may involve behaviors such as touching, kissing, and rape.

The chapter is structured as follows. First, the case study is introduced. Second, the data source is described as well as the characterization of the transportation modes. Third, the results and discussion are presented in relation to the type of crimes, place and mode of transportation, and types of precautions that students take to avoid victimization. Finally, the chapter finishes with the conclusion and policy recommendations.

\subsection{Background}

\section{The nature of sexual crimes in public transportation}

Sexual harassment and sexual violence come in many forms, and it is a common phenomenon in PT services worldwide. Since some PT environments are often places of convergence, crime opportunities, and sexual violence, it is an inherent part of the daily rhythmic flow of people passing by in these transit environments. Paradoxically, some of these sexual crimes happen in places where anonymity at particular times make these crimes possible, such as an empty bus or train station in the evening hours.

Previous research has indicated that the risk of victimization of sexual crimes and unwanted sexual behaviors varies across different types of individuals (age, gender, (dis)ability, LBGTQI status, IT literacy, previous victimization, frequency of use of public transportation, length of trip), over time (rush hours, off-peak hours, days of the week, weekends, and weekdays, seasonal differences) and by different public transportation modes and settings along the trip (Gekoski et al. 2015, 6).

Transit environments, such as bus stops or train stations can be considered as criminogenic places. In Mexico, for example, a survey by the National Survey of Victimization and Perception of Public Safety (ENVIPE, 2018), found that 43.4 percent of those interviewed indicated that they were robbed or assaulted during the use of PT in the metropolitan area of Mexico City. This is well above other crimes such as fraud or robbery at home. The survey also indicated that 90.7 percent of those interviewed felt unsafe during transit using PT. As a consequence, PT users modify mobility patterns such as changing the transportation mode or choosing an alternate stop (ENVIPE, 2017, 2018). 
Research has found that a majority of the victims of sexual harassment in transit systems are young people. The vast majority are university students aged 18 to 29 , an age group that is affected more than other age groups in regards to sexual harassment and assault (Beller, Garelik, \& Cooper, 1980; Tripathi, Borrion, \& Belur, 2017). In the next section, we discuss the case study, based on a survey of 381 university students collected in 2018 from the CU Nezahualcóyotl campus.

\section{Safety perceptions and behavior responses}

Previous research on fear of crime has evolved to suggest the existence of a complex relationship between individuals, lifestyles, as well as situational and contextual factors. The environment also plays a role in defining safety perceptions in transit environments (Otis, 2007; Lubitow et al., 2017). The vulnerability for sexual crimes differs greatly between different age groups but interacts with other factors such as gender, sexual orientation, and disability-and therefore previous victimization affects one's perceived safety. Safety perceptions also follow temporal patterns, whereby travelers often declare being more fearful when it is dark than during the day, see Chapter 5 .

Individuals who report higher levels of fear are those that are most likely to change and adapt how they move in space. Jackson and Gouseti (2012) indicates four main categories of behavioral responses to the fear of crime: avoidance behavior, protective behavior, behavioral and lifestyle adjustments, and participation in relevant collective activities. Avoidance behavior involves minimizing one's contact with certain types of people, routine activities, or places. If young riders feel unsafe travelling by bus at certain times, they may take an earlier bus or change the route. Protective behavior constitutes activities that are thought to prevent crime (putting up fences) as well as wider activities of selfprotection and safety improvement (traveling in groups). Behavioral and lifestyle adjustments involves a withdrawal from activities that are considered to be dangerous, such as taking public transportation in the evenings. Finally, collective activities include participation in groups, such as neighborhood watch programs or activities directed at elderly well-being.

\section{Hypotheses of study}

The study will examine the following hypotheses:

1. Women are more victimized than men in PT and transit environments.

2. Sexual harassment varies by type and transportation modes.

3. Safety perceptions vary by type of travelers, types of trips in buses and Metro and time of the day.

4. Travelers take precautionary measures to avoid sexual harassment in transit environments. 


\section{Javier Romero-Torres and Vania Ceccato}

\subsection{Case study}

This study is part of an international project about the perception of university students on security and victimization during transit in the public transportation system (Ceccato \& Loukaitou-Sideris, 2020). This paper reports on the case of Mexico City, using students at CU Nezahualcóyotl campus as the sample. The campus is embedded in the metropolitan area of the Valley of Mexico, in the municipality of Nezahualcóyotl belonging to the State of Mexico and boasts a population of 1,040,000 inhabitants. The campus belongs to the Autonomous University of the State of Mexico that houses 1,195 students. The majority of the students reside in surrounding municipalities in the eastern part of Mexico City such as Nezahualcóyotl, Chimalhuacán, Chalco Valley, and some municipalities (called alcaldias) of Mexico City, such as Iztapalapa (INEGI 2017).

The average travel time for students to reach the Nezahualcóyotl campus is 45 minutes with a fare payment of $16 \mathrm{MXN}$ (0.8 US\$). A third of the students take more than an hour to complete the trip, with half needing to transfer two or more times to other modes of PT. Around 19 percent of students use private modes of transport such as bicycle, motorcycle, car, or walking to arrive at the Nezahualcóyotl campus, while 81 percent use public transportation (PT). While students who use only one way to arrive on campus represent 36.2 percent, those who use two modes correspond to 41.2 percent, 19 percent complete their trip in four modes, and 3.6 percent do so with more than four modes. The higher number of transfers results in greater travel times, whereby trips with four or more sections of travel represents a duration of around 250 percent more compared with trips made in a single mode (Romero, 2014).

\section{Characterization by transportation mode}

The modes of PT that the students have access to throughout the stages of their trip include those with high standards such as the Metro and BRT (Bus Rapid Transit) and those with poor service characteristics such as vans and minibus. The latter presents levels of informality and disorganization and low standards, which Cervero (2000) classifies as paratransit, offering a service characterized by a hybrid service, man-truck and a capacity of up to 15 seats (Vuchic, 2007). For the results presented in this document, two modes of PT used by the students were considered: Metro and bus, which are defined as follows.

There are 12 Metro lines that make up the network of the Collective Transportation System (STC) of the urban area of Mexico City. Line A, Pantitlán-La $\mathrm{Paz}$, is the closest to the campus, it connects the municipalities east of Mexico City with Mexico City. The characteristics of this service are high frequencies, good service hours, and reliability. Buses are operated with a mixed vehicular configuration: vans, minibuses, and 30-seat buses; which implies a variable vehicle offer in time and space. 


\section{Characteristics of the sample of university students}

Table 7.1 shows the socio-demographic characteristics of the students, trip length and duration as well as victimization. The sample is characterized by a young sample, 98.1 percent were younger than 29 years. On average, 10 percent of the interviewees identified themselves as LGBTQI. Seventy-two percent of the interviewees identified as mixed race (mestizo), a population group prevalent in Mexico according to INEGI (2019). One out of four students takes between 15 and 30 minutes to arrive on campus, for 39.1 percent the trips take up to one hour, and for 24.3 percent the trips take up to two hours, which means that students must use motorized modes to carry out their transfers.

\subsection{Results}

As many as 90.1 percent of women declare being sexually victimized in the last three years while in transit, while for men victimization accounted for 65.2 percent (women: 92.1 percent in buses and 88.0 percent in Metro; men: 65.4 percent in buses and 64.9 percent in Metro) (Table 7.1). University students in Mexico City show the highest sexual victimization rate on buses and the second highest on the Metro when compared with those rates found in 17 other samples located in cities in five continents around the globe (for more detail see Ceccato and Loukaitou-Sideris, 2020). These results for female students in Mexico City are similar to those found in official statistics sources such as UN-Women (2018) which reports that 88.5 percent of female travelers are sexually harassed on public transportation in Mexico City. Despite these similarities, it should be noted that this study is based on a small sample of 383 university students (191 women and 188 men) travelling mostly by bus.

There is a small difference in victimization between buses and Metro for women but not for men. As many as 92.1 percent for women and 65.4 percent for men, declared to be victims of at least one sexual assault in buses, while in the Metro, the proportions of victimization are 88.0 percent and 64.9 percent, for women and men, respectively. However, it is unclear why the percentages of victimization for men are fairly constant regardless of mode of public transportation. Women who identify themselves as LGBTQI are more likely to be victimized on the Metro than in the bus. On the other hand, non-LGBTQI women are more likely to be victimized in the bus.

The proportion of sexual victimization increases with the duration of the trip (30-60 minutes reaches its peak) and then decreases again for both buses and Metro (Figure 7.1(a)). For instance, those who frequently travel by buses (5-7 trips per week) are more likely to be sexually victimized. However, we noticed an inverse pattern among those using the Metro (Table 7.1). This might be related to the types of environments (crowded carriages at peak times) and differences in guardianship experienced by the travelers in the Metro compared 


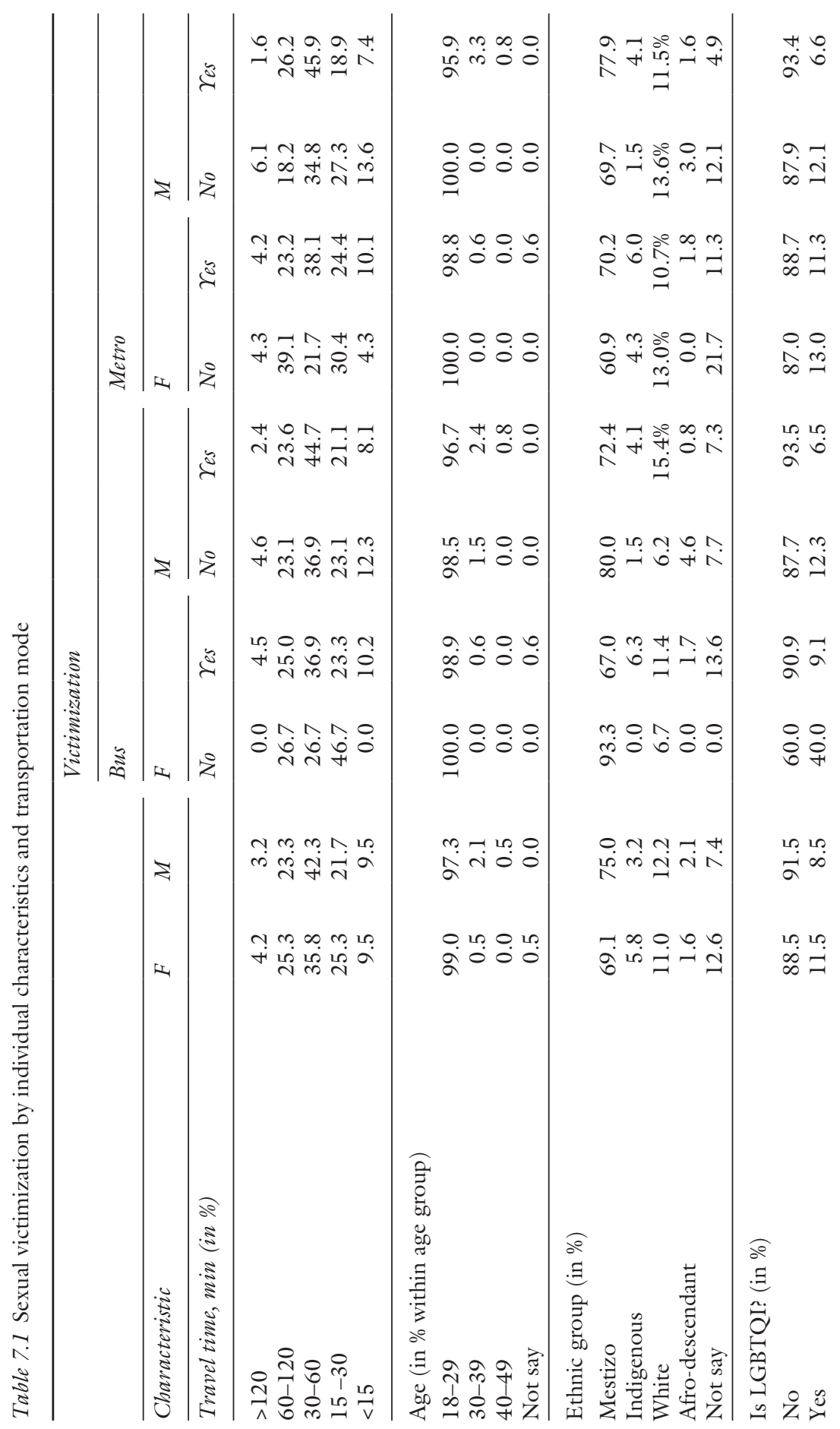




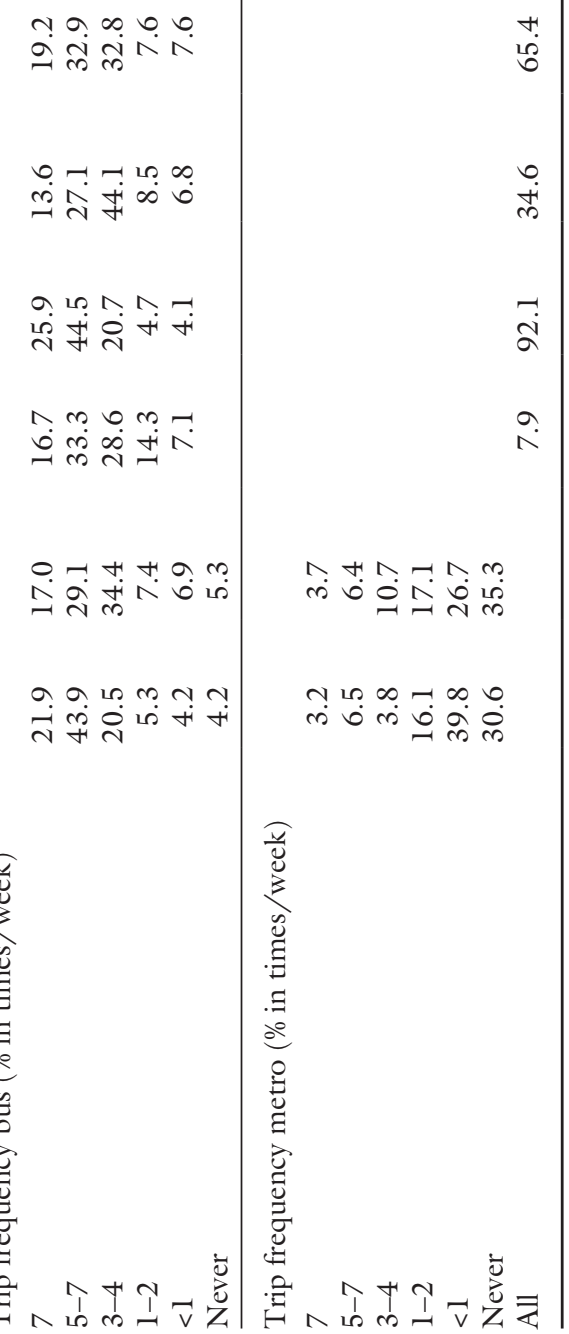

के



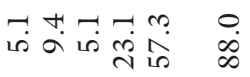

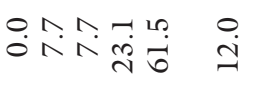

10

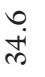

ลั

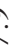




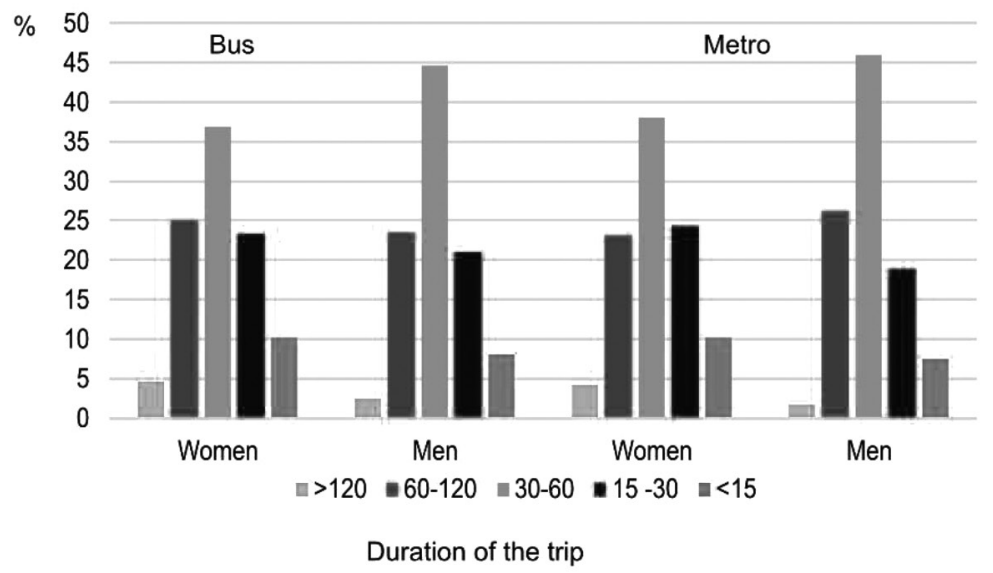

(a)

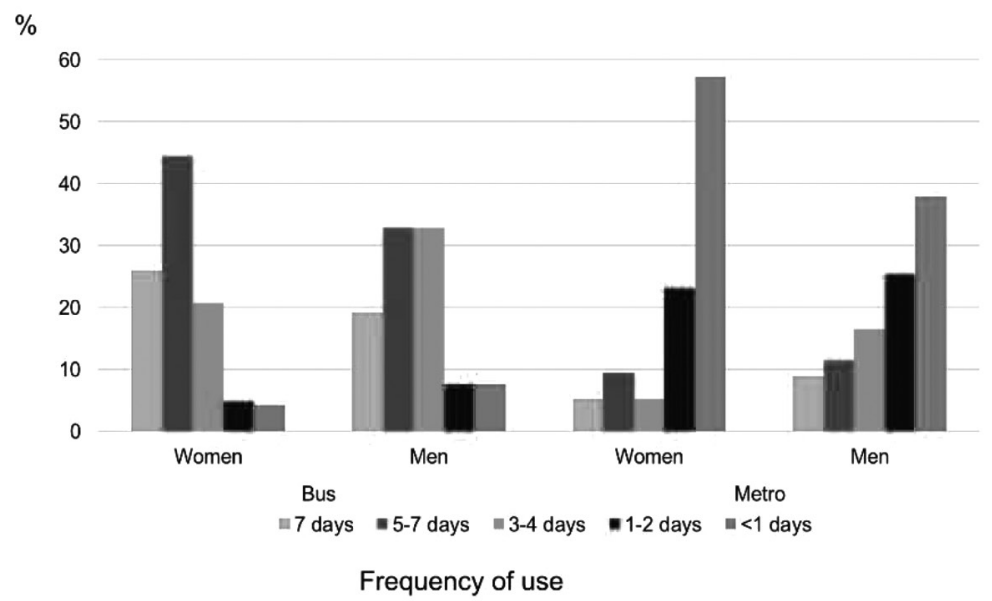

(b)

Figure 7.1 (a) Sexual victimization by duration of the trip and (b) frequency of use of PT.

with those found in buses and bus stops (Figure 7.l(b)), but also the fact that this sample comprises travelers using mostly buses (a larger sample of students using Metro would be necessary to confirm differences in victimization by transportation mode).

\section{Types of sexual harassment by location and gender}

Figure 7.2 illustrates the types of sexual victimization that students have experienced in the last three years. Verbal harassment is more frequent in buses, while non-verbal sexual harassments are more common in the Metro, with women representing most of the victims. The most common verbal sexual harassments for women are whistling, unwanted sexual teasing, and sexual remarks, while for 


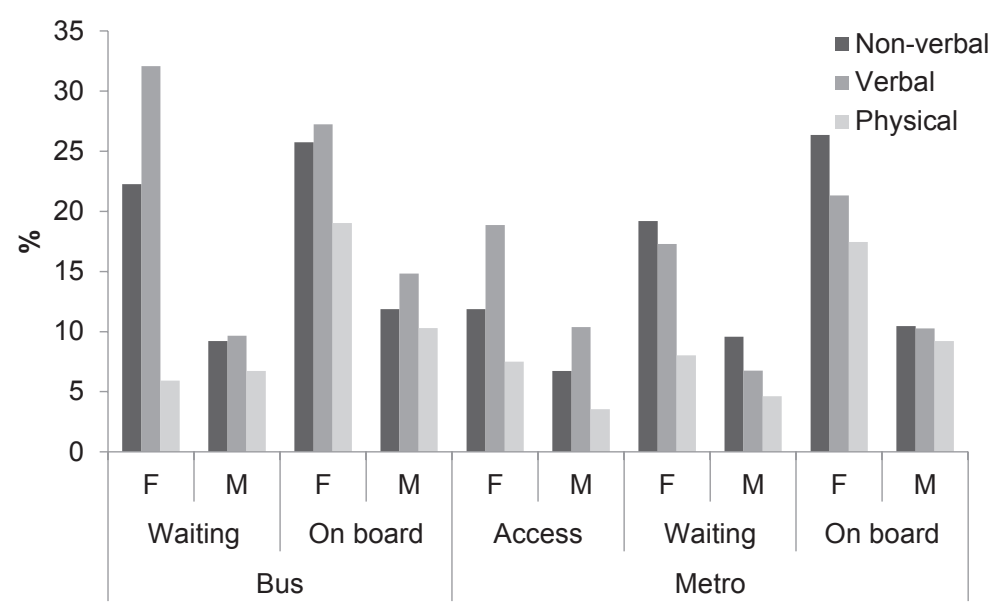

Figure 7.2 Types of sexual harassments in transit and by transportation mode. Access means on the way to/from bus stops and or Metro station.

men, the most common is to be asked to have sex with a stranger. These events often happen on the way to PT. The physical sexual crimes are the least experienced by the students, and are carried out with greater frequency on board the vehicle, in both bus and Metro. Victimization rates follow the types of transit environments in PT, they increase as the system becomes more crowded: on the way to the bus or train, platforms and stops, and finally on board the vehicle.

Table 7.2 shows other types of sexual victimization along the trip. Comments and whistles are the sexual assaults more commonly found (63.2 and 60.5 percent respectively) against women while waiting for the bus, followed by gestures and sending kisses. Against men it is more common whistling and stalking (with 22.3 percent and 17 percent, respectively). While on board the bus, gestures ( 63.3 percent) towards women and obscene language (31.4 percent) towards men are the most frequent types of offences. Physical sexual violence is the most common type of victimization declared by the students in both modes of PT. Asking to have sex is the most type of victimization by women (57.1 percent) and men (42.9 percent) on the way to the bus; sending kisses to women (34 percent) and harassment (17.6 percent) towards men are the most common types of offence while waiting, and gestures towards them and obscene language towards them persist while they remain inside the bus. During the use of the Metro, the victimization is maintained throughout the three stages, possibly explained by the homogeneity in the facilities of this transportation mode; while in the bus the differentiation persists, the conditions of the stops and interior of the bus are different. These findings suggest that the offenders may plan their actions towards their victims according to the transportation mode and the environments they involve. 


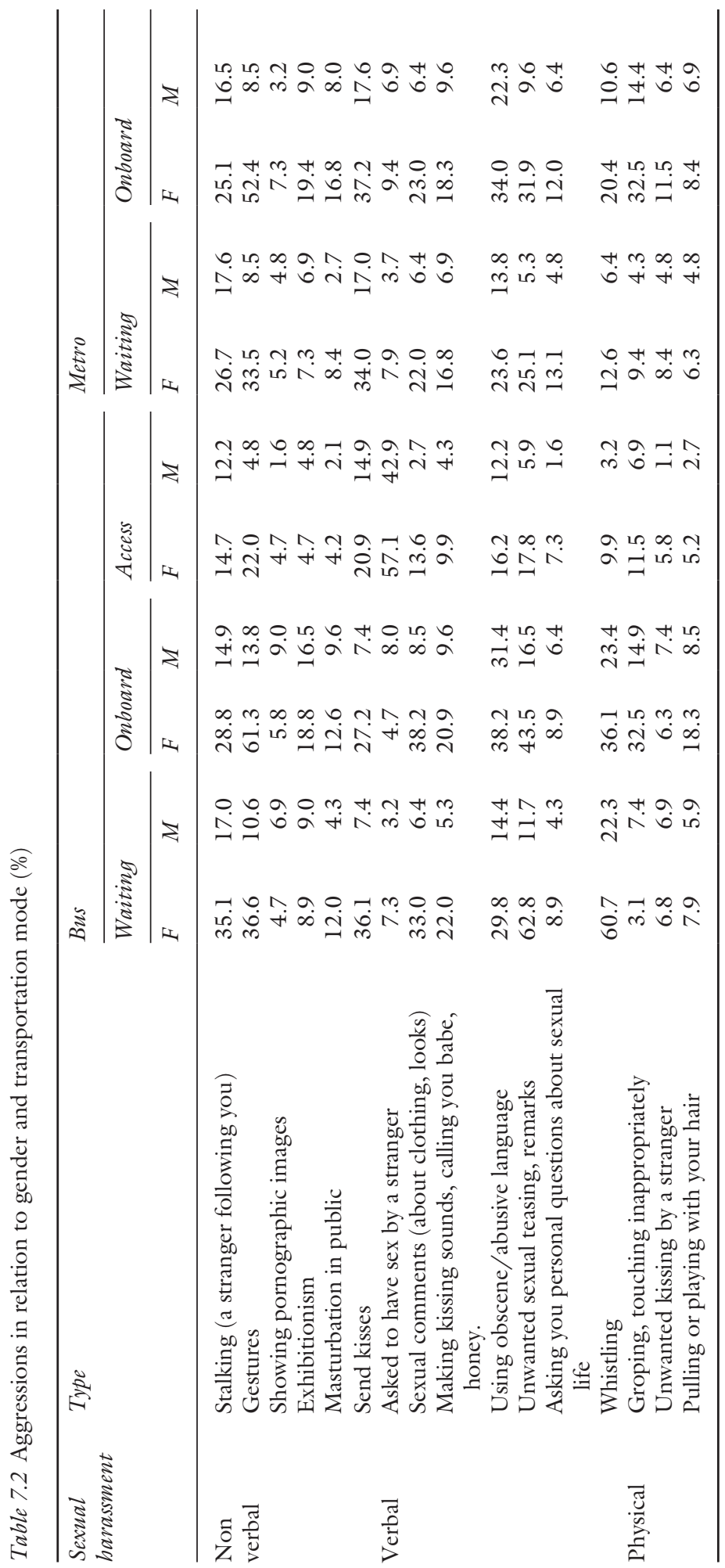




\section{Safety perceptions-day and night}

Only 1 percent of women and 7 percent of men declare feeling "always" or "often" safe after dark on the bus in Mexico City. Similarly, at the bus stop or walking to/from bus stop, only 2 percent of female students and 4 percent of male students declare feeling "always" or "often" safe after dark-these percentages are the lowest safest levels declared by students taking part in the global study comparing 18 city-samples around the world (Ceccato and Loukaitou-Sideris, 2020).

Figure 7.3 shows safety perceptions declared by university students by gender in Mexico City when using bus and Metro, by settings and by day and night. Men and women declare feeling less safe during evening/night hours than during the day. For buses, 36 percent of the students indicated that they sometimes felt safe waiting and on board the bus during the day. As many
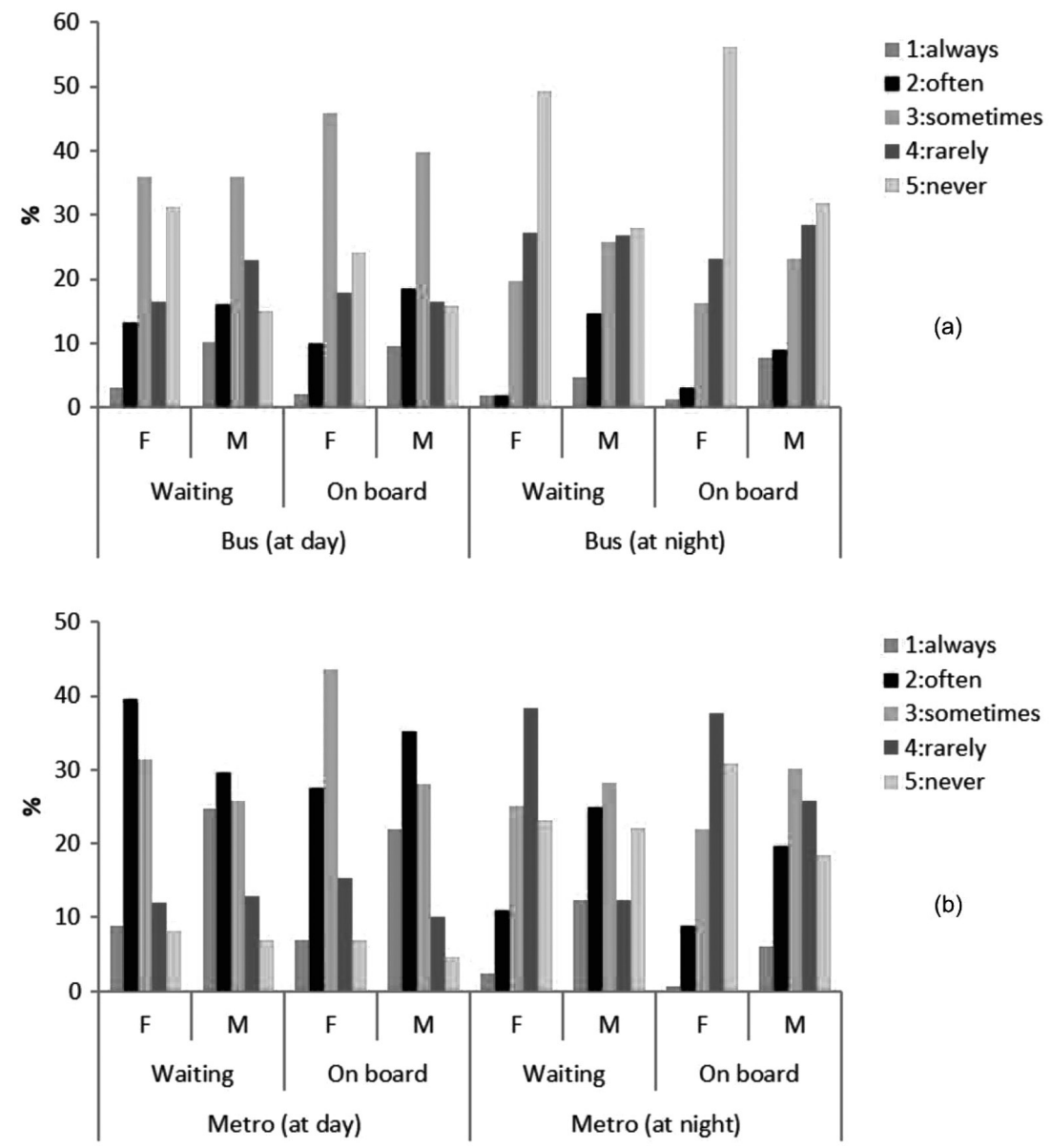

Figure 7.3 Perceived safety by gender, transportation mode, settings and time of day. 


\section{6}

as 47.6 percent of them indicated sporadic levels (rarely and never) of safety at the stop; those proportions decrease to 42.1 percent and 32.3 percent when students are on board the bus. Note that while for the frequency levels of safety always and often changes for men from 26.2 percent (waiting for the bus) to 28 percent (on board), for women the proportion decreases from 16.4 percent (waiting for the bus) to 12.2 percent (on board), indicating an increased risk for certain types of physical sexual harassment on board, such as groping.

Similarly, during the evening/night, the frequency of feeling less safe increases as they move from waiting at the bus stop to on board (waiting: 29 percent at night, while on board the bus the proportion is 37.3 percent). This indicates that, on board buses, women are more often victimized (in quantity or intensity) than when they are at the bus stop. Additionally, they might be at higher risk of other types of crimes such as thefts, pickpocketing on board buses. During the day, men declared feeling slightly safer on board the bus compared with waiting for the bus. In regard to overnight trips, they also feel less safe than during the day, whereby the perception of safety decreased by 28.1 percent on board the bus during the night compared with the day. Men feel less safe during the night and this insecurity is most likely explained by an increased risk of overall crimes, such as robbery or assaults, and to a lesser extent explained by sexual assaults.

Figure 7.3 shows higher levels of safety declared by the university students when using the Metro by day than those using the Metro by evening/night. According to the stage of the trip during the day, the safety experienced by women is reduced by 14 percent on board the Metro in relation to waiting for it, this is contrary to the increase of 2.7 percent that has been identified for men. What can be deduced from this is that certain types of sexual assaults intensify against women aboard the Metro car. For trips taken during evening/ nights, safety decreases from waiting to onboard by 19.7 percent for women and 11.5 percent for men.

\section{Precautions}

In Mexico City, travelling during the day, being accompanied by other people, and avoiding wearing jewelry, are common measures taken by students using the bus and Metro (Table 7.3). These precautions reflect lower levels of safety perceptions on the Metro and/or on the way to the Metro stations during the night (Figure 7.3). A small percentage (4.5 percent) of respondents even felt the need to also carry some type of weapon. While avoiding certain Metro stations or lines was a precaution taken by a higher percentage of students than avoiding certain bus lines, this is possibly explained by the fact that many students are captive bus commuters, with the bus being their only option to reach the campus. Avoiding carrying a wallet was more frequent for Metro riders, possibly because of crowding, not only on board, but also at the platforms and corridors during rush hour. 
Table 7.3 Mexico City student precautions while travelling on public transit (\%)

\begin{tabular}{lrc}
\hline Precautions & Bus & Metro \\
\hline Travel in the day & 11.7 & 11.5 \\
Always with someone & 10.9 & 15.1 \\
Avoid certain station or lines & 7.9 & 23.4 \\
Wearing certain clothes & 9.8 & 12.9 \\
Do not wear jewelry & 16.2 & 16.4 \\
Avoid carrying wallet & 8.9 & 14.5 \\
Carry a weapon & 4.5 & 5.1 \\
Wait for public transportation only in well-lit places & 15.2 & - \\
Wait for public transportation with other users & 14.9 & - \\
Other & - & 1.2 \\
\hline
\end{tabular}

Source: Authors.

\subsection{Discussion of results}

Women are victims of sexual assaults in greater proportion than men, confirming our first hypothesis. The risk of men being sexually harassed seems to be independent on the mode of transportation while, for women, the risk decreases when using the Metro compared with the bus. As suggested by the second hypothesis, victimization varies by type of sexual harassment (the most common is verbal sexual harassment) in both bus and Metro but may vary along the trip. Students were victimized by verbal and non-verbal types of harassment during their trip to the transit stop or when waiting for the transit vehicle. Some students also suffered physical harassment, while on board the transit vehicle.

In terms of our third hypothesis, we found that safety perceptions vary by type of travelers (women declare feeling more fearful than men) and types of trips in buses and Metro and on the way to the transport nodes (bus stops and Metro stations). Considering the transportation mode, the perception of safety is rated much higher when the user is onboard the Metro car in comparison with waiting on the platform. Safety perception decreases when trips are made in the evening/night in comparison with daytime.

Our fourth hypothesis was also confirmed: we found travelers take precautionary measures to avoid sexual harassment in transit environments. Signals of what one may call 'dysfunctional fear' can be clearly witnessed when one starts avoiding certain places (in this case, certain stations or lines) or certain times (for example, traveling alone during the evening). The findings show indications of behavioral adaptation as suggested by Jackson and Gouseti (2012), such as thinking about what clothes to wear, not choosing to carry a wallet, or not wearing jewelry.

\subsection{Conclusions and recommendations}

This chapter reports experiences of sexual victimization and perception of safety in public transportation (PT) by young people in eastern Mexico City, Mexico, 


\section{Javier Romero-Torres and Vania Ceccato}

using the answers of a survey carried out on 381 university students. Findings show that women are more victimized than men in PT and transit environments. The proportion of victimization in Mexico City is the highest among college students, compared with a survey of 17 cities across five continents carried out by Ceccato and Loukaitou-Sideris (2020). Such high victimization also varies by type of sexual harassment, transportation mode, length of trip, frequency of use of PT and transit settings (on board, waiting for the bus, on the way to Metro/bus stops). Students declared being more fearful during evening and nights than during the day, which leads them to take precautionary measures against potential victimization, such as avoiding travel during the evening, avoiding certain routes, making use of well-lit stops/stations, travelling with others, or even carrying a weapon. The above raises the issues of poor safety conditions as an impediment to the students' quality of life and, in general, the external costs of crime on mobility and on PT systems. Although the generalizability of this study is limited by the small sample size (respondents, especially among Metro users and area of study), it could serve as the basis for future large-scale surveys on transit environments in Mexico and elsewhere.

Safety perceptions and levels of victimization, in general, depend on the transportation mode and the time of travel (day or night), therefore public policies aimed at reducing sexual harassment and improving safety for travelers should consider these situational aspects when tackling sexual harassment in PT environments. Public policies aimed at reducing sexual transit crimes should consider different transportation modes at different stages of the trips. Knowing in more detail where and when most sexual harassment occurs is fundamental for future research, and also creates a set of realistic safety strategies to improve transit environments of young travelers in Mexico City.

Maintenance of the transportation infrastructure to increase the perception of user safety is also necessary. This can be achieved by improving lighting conditions in stations, stops, or modal exchange areas, and along pedestrian routes or establishments where there is a constant flow of people. It would be desirable to have security guards/police surveillance in and around the transportation systems, especially at stops, stations for bus routes, and on board wagons for the Metro system. From the above, constant monitoring should be carried out to assess the impact of these implementations on users' safety to redefine the strategies and modify them in order to provide feedback for mitigation measures. It is fundamental to consider users' perspectives when tackling safe conditions in PT environments, in particular the needs of women who are mostly likely to be targets of sexual harassment and have their life opportunities reduced by impaired mobility when using PT.

\section{References}

Beller, A., Garelik, S., \& Cooper, S. (1980). Sex crimes in the subway. Criminology, 18, $35-52$.

Ceccato, V., \& Loukaitou-Sideris, A. (2020). Transit Crime and Sexual Violence in Cities: International Evidence and Prevention. London: Routledge. 
Cervero, R. (2000). Informal Transport in the Developing World. United Nations Centre for Human Settlements (Habitat).

CONAPRED, Comisión Nacional para Prevenir la Discriminación (2009). La discriminación y violencia contra las mujeres en el transporte de la Ciudad de México. Documento de Trabajo No. E-18-2009, México D.F.

ENVIPE, Encuesta Nacional de Victimización y Percepción sobre Seguridad Pública (2017). Report, Instituto Nacional de Estadística y Geografía, México.

ENVIPE, Encuesta Nacional de Victimización y Percepción sobre Seguridad Pública (2018). Report, Instituto Nacional de Estadística y Geografía, México.

Gekoski, A., Jacqueline, M., Gray, M. H., Horvath, S. E., Aliye, E., \& Adler, J. (2015). 'What works' in reducing sexual harassment and sexual offences on public transport nationally and internationally: A rapid evidence assessment. Project Report. Middlesex University; British Transport Police; Department for Transport, London.

INEGI, Instituto Nacional de Estadística y Geografía (2017). Encuesta Origen-Destino en hogares de la Zona Metropolitana del Valle de México. Mexico: Aguascalientes.

INEGI, Instituto Nacional de Estadística y Geografía (2019). Mexico: Aguascalientes.

Jackson, J., \& Gouseti, I. (Eds.) (2012). Fear of Crime: An Entry to the Encyclopedia of Theoretical Criminology. Chichester: Wiley-Blackwell. http://eprints.mdx.ac.uk/15219/ (accessed 9 December 2019). www.mdx.ac.uk/_data/assets/pdf_file/0019/155800/ What-Works-in-Reducing-Sexual-Harassment-and-Sexual-Offences-on-Public-TransportNationally-and-Internationally.pdf (accessed 9 December 2019).

Lubitow, A., Carathers, J., Kelly, M., \& Abelson, M. (2017). Transmobilities: mobility, harassment, and violence experienced by transgender and gender nonconforming public transit riders in Portland, Oregon. Gender. Place \& Culture, 24, 1398-1418.

Otis, M. D. (2007). Perceptions of victimization risk and fear of crime among lesbians and gay men. Journal of Interpersonal Violence, 22, 198-217.

Romero, J. (2014). Definición de la ruta de transporte escolar de la UAP Nezabualcóyotl. Informe técnico, UAEM.

TRF-Thomson Reuters Foundation (2014). Most dangerous transport systems for women. Available at: http://news.trust.org//spotlight/most-dangerous-transport-systems-forwomen/ (accessed 24 May 2018).

Tripathi, K., Borrion, H., \& Belur, J. (2017). Sexual harassment of students on public transport: an exploratory study in Lucknow, India. Crime Prevention and Community Safety, $19,240-250$.

UN-Habitat (2012). Programa de las Naciones Unidas para los Asentamientos Humanos. Estado de las Ciudades de América Latina y el Caribe. www.cinu.mx/minisitio/ Informe_Ciudades/SOLACC_2012_web.pdf (accessed 29 November 2019).

UN-Women (2018). Encuesta sobre la violencia sexual en el transporte y otros espacios públicos en la Ciudad de México. www.unwomen.org/es (accessed 2 December 2019).

Vuchic, V. (2007). Urban Transit, Systems and Technology. USA: John Wiley. 